\title{
Synthesis and Crystal Structure of 6-Bromo-2-(furan-2-yl)-3- (prop-2-ynyl)-3H-imidazo[4,5-b]pyridine
}

\author{
Youssef Kandri Rodi, ${ }^{1}$ Santiago V. Luis, ${ }^{2}$ Inés Martí, ${ }^{2}$ \\ Vicente Martí-Centelles, ${ }^{2}$ and Younès Ouzidan ${ }^{1}$ \\ ${ }^{1}$ Laboratoire de Chimie Organique Appliquée, Faculté des Sciences et Techniques, Université Sidi Mohamed Ben Abdellah, \\ Fès BP 2202, Morocco \\ ${ }^{2}$ Universitat Jaume I, Departamento de Química Inorgánica y Orgánica, Avenida Sos Baynat, \\ S/N, 12071 Castellón, Spain
}

Correspondence should be addressed to Youssef Kandri Rodi; youssef_kandri_rodi@yahoo.fr and Santiago V. Luis; luiss@qio.uji.es Received 29 May 2013; Revised 29 July 2013; Accepted 30 July 2013

Academic Editor: Nigam P. Rath

Copyright ( $) 2013$ Youssef Kandri Rodi et al. This is an open access article distributed under the Creative Commons Attribution License, which permits unrestricted use, distribution, and reproduction in any medium, provided the original work is properly cited.

The crystal and molecular structure of 6-bromo-2-(furan-2-yl)-3-(prop-2-ynyl)-3H-imidazo[4,5-b]pyridine $\left(\mathrm{C}_{13} \mathrm{H}_{8} \mathrm{BrN}_{3} \mathrm{O}\right)$ has been investigated from single crystal X-ray diffraction data. The primary focus is to investigate the molecular geometry of this compound in the solid state along with the associated intermolecular hydrogen bonding and related $\pi-\pi$ interactions present in the crystal packing. This compound crystallizes in the monoclinic space group $P 2_{1} / n$ with cell parameters: $a=4.39655(19) \AA$, $b=13.5720(5) \AA, c=20.0471(5) \AA, \beta=94.753(3), V=1192.10(7) \AA^{3}, D=1.683 \mathrm{~g} \cdot \mathrm{cm}^{-3}$, and $\mathrm{Z}=4$. The crystal structure is stabilized by $\pi-\pi$ interactions and intermolecular $\mathrm{C}-\mathrm{H} \cdots \mathrm{N}$ and $\mathrm{C}-\mathrm{H} \cdots \mathrm{O}$ interactions.

\section{Introduction}

The imidazo[4,5-b]pyridine moiety is an important heterocyclic nucleus having been used extensively in medicinal chemistry. In fact, different compounds derived from this structure have been tested for their potential as anticancer [1], tuberculostatic [2], antimitotic [3], and antineuroinflammatory activities [4].

Due to their great importance, many synthetic strategies have been developed to obtain a variety of substituted structures of this class. The most popular synthetic approach generally involves the cyclocondensation of 2,3-pyridinediamine with carboxylic acid derivatives or with aldehydes $[5,6]$. Recently, an ecofriendly synthetic approach including an oxidation in aqueous medium has been claimed [7].

In a previous study, we reacted 6-bromo-2-(furan-2yl)-3H-imidazo[4,5-b]pyridine with benzyl chloride in the presence of a catalytic quantity of tetra- $n$-butylammonium bromide, under mild conditions, to form 3-benzyl-6-bromo2-(furan-2-yl)-3H-imidazo[4,5-b]pyridine [8]. In this work, we have synthesized the 3-prop-2-ynyl analogue which is 6-bromo-2-(furan-2-yl)-3-(prop-2-ynyl)-3H-imidazo[4,5b]pyridine (1) (Scheme 1). Owing to the potential biological activities of imidazo[4,5-b]pyridine derivatives, a clear need exists for the preparation of new compounds. In this regard, compound $\mathbf{1}$ presents some interesting features in the search for new biologically active substances as it contains an additional heterocyclic ring and an alkyne group for easy modification.

\section{Material and Methods}

6-Bromo-2-furyl-3H-imidazo[4,5-b]pyridine $\quad(0.30 \mathrm{~g}, \quad 1.13$ $\mathrm{mmoL})$ was dissolved in DMF $(15 \mathrm{~mL})$ and potassium carbonate $(0.2 \mathrm{~g}, 1.48 \mathrm{mmol})$, and tetra- $n$-butylammonium bromide $(0.04 \mathrm{~g}, 0.1 \mathrm{mmol})$ and propargyl bromide $(0.12 \mathrm{~mL}$, $1.36 \mathrm{mmoL}$ ) were then added. Stirring was continued at room temperature for $12 \mathrm{~h}$. The mixture was filtered, and the solvent was removed under reduced pressure. The residue was chromatographed on a column of silica gel with ethyl 


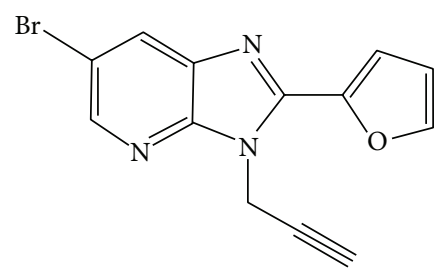

SCheme 1: Compound 1. acetate-hexane (1/2) as eluent. Compound $\mathbf{1}$ was obtained as yellow solid.

Single crystals of $\mathbf{1}, \mathrm{C}_{13} \mathrm{H}_{8} \mathrm{BrN}_{3} \mathrm{O}$, were crystallized from ethanolic solution. A suitable crystal was selected and measured on an Agilent SuperNova Atlas Dual Source, Agilent Technologies diffractometer using the CrysAlisPro software. The crystal was kept at 199.95(10) K during data collection. Using Olex2 [9], the structure was solved with the SHELXS [10] structure solution program using direct methods and refined with the SHELXL [10] refinement package using least squares minimisation. Nonhydrogen atoms are refined with anisotropic displacement parameters. The molecular connectivity and the crystal packing diagram were drawn using the Mercury (CCDC) program [11] and PyMol [12]. Geometrical calculations were done using Mercury (CCDC) program.

\section{Results and Discussion}

The details of the crystal data, data collection, and structure refinements are shown in Table 1 and the unique molecule in the crystal structure of 1 in Figure 1.

This compound crystallizes in the monoclinic space group $P 2_{1} / n$ with four molecules in the unit cell. The core heterocyclic structure of the molecule is approximately planar with deviations lower than $0.064 \AA$ from the mean plane. The molecular geometry is stabilized by intermolecular $\mathrm{C}-\mathrm{H} \cdots \mathrm{N}$ and $\mathrm{C}-\mathrm{H} \cdots \mathrm{O}$ interactions which contribute to the stability of the crystal packing (Figure 2). Those interactions involve the relatively acidic hydrogen atom of the terminal alkyne.

An analysis of the crystal packing shows the presence of intermolecular $\pi-\pi$ interactions between the imidazole ring and the pyridine ring of two contiguous molecules. This interaction has a $3.635 \AA$ centroid-centroid distance (see Figure 3).

These $\pi-\pi$ interactions generate arrays of parallel aromatic subunits along the crystallographic a-direction (Figure 4), while $\mathrm{C}-\mathrm{H} \cdots \mathrm{N}$ and $\mathrm{C}-\mathrm{H} \cdots \mathrm{O}$ interactions form a zigzag structure along the $b$ direction (Figure 5).

A general view of the crystal packing of compound $\mathbf{1}$ is summarized in Figure 6, where all intermolecular interactions are shown. The arrays formed by $\pi-\pi$ interactions along the crystallographic $a$-direction are shown in green colour. Besides, intermolecular $\mathrm{C}-\mathrm{H} \cdots \mathrm{N}$ and $\mathrm{C}-\mathrm{H} \cdots \mathrm{O}$ interactions are represented with yellow dotted lines providing the generation of a zigzag structure (blue colour) along the $b$ direction.
TABLE 1: Crystal data and structure refinement for compound $\mathbf{1}$.

\begin{tabular}{lc}
\hline Empirical formula & $\mathrm{C}_{13} \mathrm{H}_{8} \mathrm{BrN}_{3} \mathrm{O}$ \\
\hline Formula weight & 302.13 \\
Temperature/K & $199.95(10)$ \\
Crystal system & Monoclinic \\
Space group & $P 2_{1} / n$ \\
$a / \AA$ & $4.39655(19)$ \\
$b / \AA$ & $13.5720(5)$ \\
$c / \AA$ & $20.0471(5)$ \\
$\beta /{ }^{\circ}$ & $94.753(3)$ \\
Volume/ ${ }^{3}$ & $1192.10(7)$ \\
$Z$ & 4 \\
$D_{\text {calc }}$ mg/mm & \\
m/mm & -1 \\
$F(000)$ & 1.683 \\
Crystal size/mm & 4.629 \\
$2 \Theta$ range for data collection & 600.0 \\
Index ranges & $-5 \leq \mathrm{h} \leq 4,-16 \leq k \leq 16,-24 \leq 1 \leq 24$ \\
Reflections collected & 11229 \\
Independent reflections & $2362[R(\mathrm{int})=0.0455]$ \\
Data/restraints/parameters & $2362 / 0 / 163$ \\
Goodness-of-fit on $F^{2}$ & 1.201 \\
Final $R$ indexes $[I \geq 2 \sigma(I)]$ & $R_{1}=0.0389, \mathrm{w} R_{2}=0.1052$ \\
Final $R$ indexes [all data] & $0.0488, \mathrm{w} R_{2}=0.1092$ \\
Largest diff. peak/hole/e $\AA^{-3}$ & $0.47 /-0.38$ \\
\hline & \\
\hline
\end{tabular}

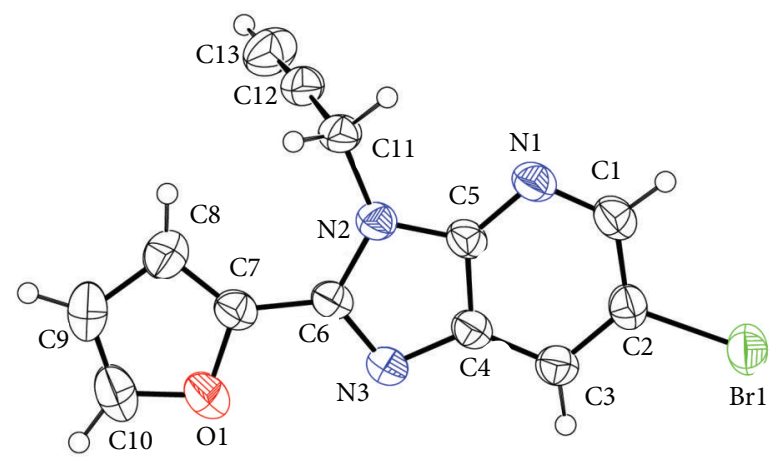

FIgURE 1: Projection view of $\mathbf{1}$.

Tables 2 and 3 summarize the crystallographic data with all bond lengths and bond angles for compound $\mathbf{1}$.

\section{Conclusions}

The compound 6-bromo-2-(furan-2-yl)-3-(prop-2-ynyl)$3 \mathrm{H}$-imidazo[4,5-b]pyridine has been synthesized as a 


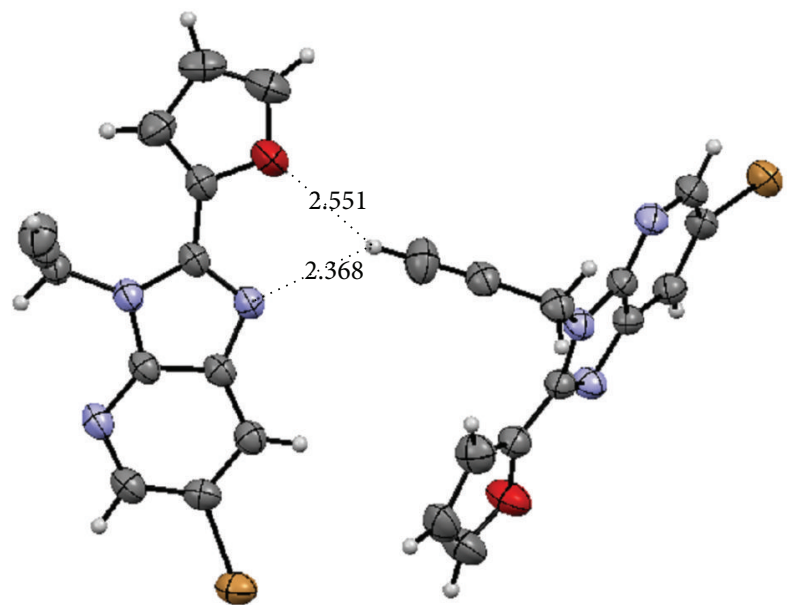

Figure 2: Intermolecular $\mathrm{C}-\mathrm{H} \cdots \mathrm{N}$ and $\mathrm{C}-\mathrm{H} \cdots \mathrm{O}$ interactions for compound $\mathbf{1 .}$
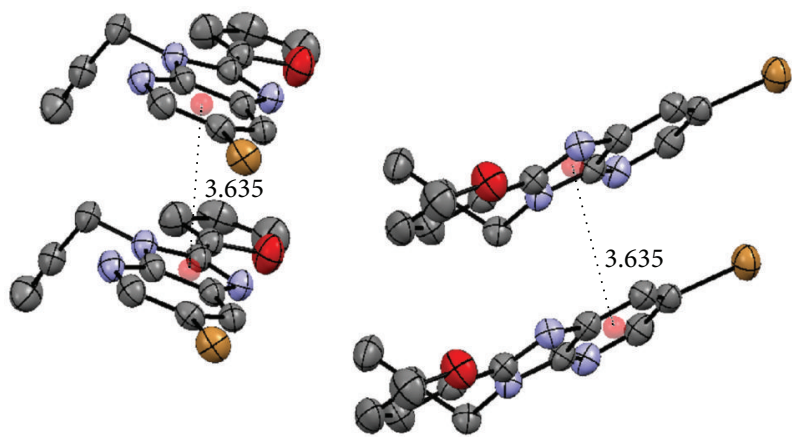

FIgURE 3: Intermolecular $\pi-\pi$ interactions.

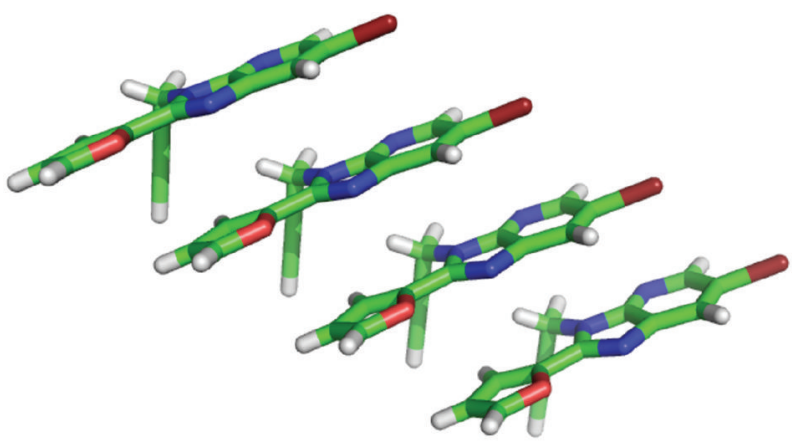

FIGURE 4: Arrays of parallel aromatic subunits formed by intermolecular $\pi-\pi$ interactions.

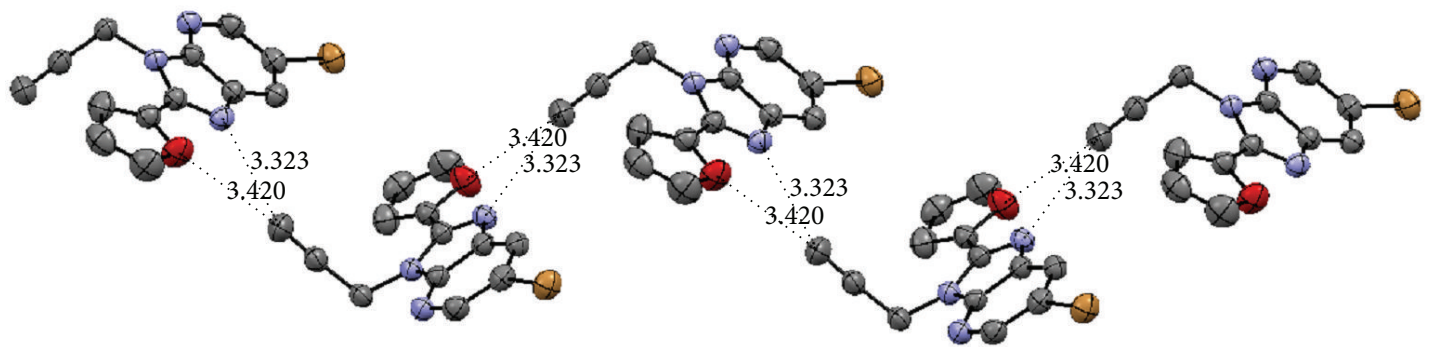

Figure 5: Intermolecular C-H $\cdots \mathrm{N}$ and $\mathrm{C}-\mathrm{H} \cdots \mathrm{O}$ interactions forming a zigzag structure along the $b$ direction. 


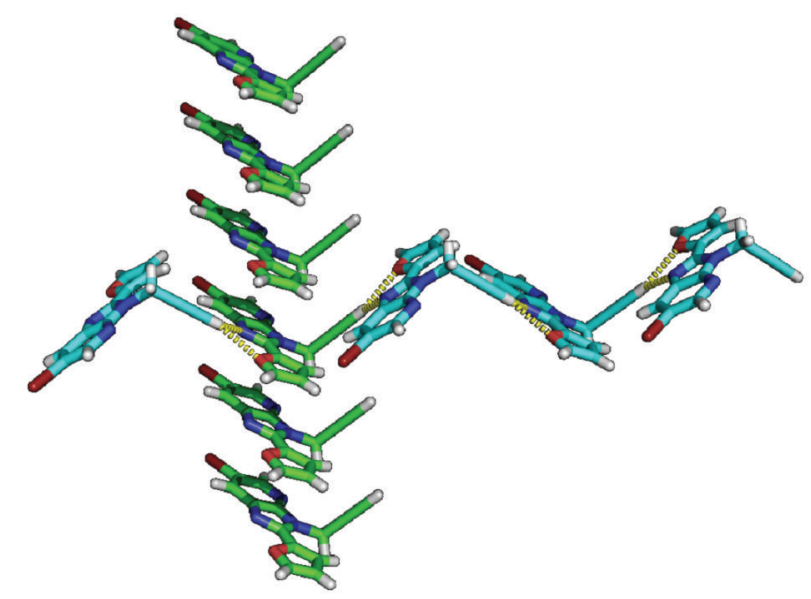

FIgURE 6: Arrays formed by $\pi-\pi$ interactions (green colour) along the crystallographic $a$-direction, and intermolecular C-H... N and C$\mathrm{H} \cdots \mathrm{O}$ interactions (showed with yellow dotted lines) forming a zigzag structure (blue colour) along the $b$ direction.

TABLE 2: Bond lengths for compound 1.

\begin{tabular}{|c|c|c|}
\hline Atom & Atom & Length/Å \\
\hline Br1 & $\mathrm{C} 2$ & $1.894(3)$ \\
\hline $\mathrm{C} 1$ & $\mathrm{C} 2$ & $1.391(5)$ \\
\hline $\mathrm{Cl}$ & N1 & $1.337(5)$ \\
\hline $\mathrm{C} 2$ & C3 & $1.386(5)$ \\
\hline C3 & $\mathrm{C} 4$ & $1.395(5)$ \\
\hline $\mathrm{C} 4$ & C5 & $1.403(4)$ \\
\hline $\mathrm{C} 4$ & N3 & $1.379(4)$ \\
\hline C5 & N1 & $1.332(4)$ \\
\hline C5 & $\mathrm{N} 2$ & $1.380(4)$ \\
\hline C6 & C7 & $1.445(5)$ \\
\hline C6 & N2 & $1.387(4)$ \\
\hline C6 & N3 & $1.319(4)$ \\
\hline C7 & C8 & $1.340(5)$ \\
\hline $\mathrm{C} 7$ & $\mathrm{O} 1$ & $1.366(4)$ \\
\hline $\mathrm{C} 8$ & C9 & $1.447(6)$ \\
\hline C9 & $\mathrm{C} 10$ & $1.307(6)$ \\
\hline $\mathrm{C} 10$ & O1 & $1.353(5)$ \\
\hline C11 & $\mathrm{C} 12$ & $1.465(5)$ \\
\hline C11 & N2 & $1.462(4)$ \\
\hline $\mathrm{C} 12$ & $\mathrm{C} 13$ & $1.178(5)$ \\
\hline
\end{tabular}

new starting material for the development of products with biomedical activities. Its crystal structure has been determined with good precision and accuracy. The molecular structure and crystal packing are stabilized by intermolecular $\mathrm{C}-\mathrm{H} \cdot \cdots \mathrm{N}$ and $\mathrm{C}-\mathrm{H} \cdot \mathrm{O} \mathrm{O}$ hydrogen bonds and intermolecular $\pi-\pi$ interactions with the generation of an infinite network.
TABLE 3: Bond angles for compound 1.

\begin{tabular}{lccc}
\hline Atom & Atom & Atom & Angle $^{\circ}$ \\
\hline N1 & C1 & C2 & $123.4(3)$ \\
C1 & C2 & Br1 & $118.1(3)$ \\
C3 & C2 & Br1 & $119.5(3)$ \\
C3 & C2 & C1 & $122.3(3)$ \\
C2 & C3 & C4 & $115.3(3)$ \\
C3 & C4 & C5 & $117.7(3)$ \\
N3 & C4 & C3 & $132.0(3)$ \\
N3 & C4 & C5 & $110.3(3)$ \\
N1 & C5 & C4 & $127.6(3)$ \\
N1 & C5 & N2 & $126.6(3)$ \\
N2 & C5 & C4 & $105.8(3)$ \\
N2 & C6 & C7 & $123.7(3)$ \\
N3 & C6 & C7 & $123.2(3)$ \\
N3 & C6 & N2 & $113.1(3)$ \\
C8 & C7 & C6 & $135.6(3)$ \\
C8 & C7 & O1 & $110.6(3)$ \\
O1 & C7 & C6 & $113.8(3)$ \\
C7 & C8 & C9 & $104.7(4)$ \\
C10 & C9 & C8 & $107.3(4)$ \\
C9 & C10 & O1 & $110.9(4)$ \\
N2 & C11 13 & C12 & $111.9(3)$ \\
C5 & C12 & C11 & $176.4(4)$ \\
C5 & N1 & C1 & $113.7(3)$ \\
C5 & N2 61 & $105.8(3)$ \\
C6 & C11 & $124.4(3)$ \\
C6 & C1 & $129.7(3)$ \\
C10 & C7 & $105.0(3)$ \\
\hline & & & $106.4(3)$ \\
\hline
\end{tabular}

\section{Acknowledgments}

Financial support has been provided by GV (PROMETEO/2012/020) and MINECO (CTQ2012-38543-C03-01). 


\section{References}

[1] Z. Guo, J. E. Tellew, R. S. Gross et al., "Design and synthesis of tricyclic imidazo[4,5-b]pyridin-2-ones as corticotropin-releasing factor-1 antagonists," Journal of Medicinal Chemistry, vol. 48, no. 16, pp. 5104-5107, 2005.

[2] L. Bukowski and M. Janowiec, "3-(2-Imidazo[4,5-b]pyridine) propionic acid and some of its derivatives with suspected tuberculostatic activity," Pharmazie, vol. 44, no. 4, pp. 267-269, 1989.

[3] G. Aridoss, S. Balasubramanian, P. Parthiban, and S. Kabilan, "Synthesis and in vitro microbiological evaluation of imidazo (4,5-b) pyridinylethoxypiperidones," European Journal of Medicinal Chemistry, vol. 41, no. 2, pp. 268-275, 2006.

[4] J. Ock, S. Kim, K.-Y. Yi et al., "A novel anti-neuroinflammatory pyridylimidazole compound KR-31360," Biochemical Pharmacology, vol. 79, no. 4, pp. 596-609, 2010.

[5] P. K. Dubey, R. V. Kumar, S. M. Kulkarni, H. G. Sunder, G. Smith, and C. H. L. Kennard, "Unambiguous structural assignment of monoanils obtained from 2,3-pyridinediamines," Indian Journal of Chemistry B, vol. 43, pp. 952-956, 2004.

[6] D. W. Robertson, E. E. Beedle, J. H. Krushinski et al., "Structureactivity relationships of arylimidazopyridine cardiotonics; synthesis and inotropic activity of benzthienyl- and naphthylsubstituted imidazopyridines and purines," European Journal of Medicinal Chemistry, vol. 21, pp. 223-229, 1986.

[7] R. P. Kale, M. U. Shaikh, G. R. Jadhav, and C. H. Gill, "Ecofriendly and facile synthesis of 2-substituted-1H-imidazo[4,5b]pyridine in aqueous medium by air oxidation," Tetrahedron Letters, vol. 50, no. 16, pp. 1780-1782, 2009.

[8] Y. Ouzidan, Y. K. Rodi, H. Zouihri, E. M. Essassi, and S. W. Ng, "3-Benzyl-6-bromo-2-(2-furyl)-3H-imidazo[4,5-b]pyridine," Acta Crystallographica E, vol. 66, no. 7, p. o1874, 2010.

[9] O. V. Dolomanov, L. J. Bourhis, R. J. Gildea, J. A. K. Howard, and H. Puschmann, "OLEX2: a complete structure solution, refinement and analysis program," Journal of Applied Crystallography, vol. 42, no. 2, pp. 339-341, 2009.

[10] G. M. Sheldrick, "A short history of SHELX," Acta Crystallographica A, vol. 64, no. 1, pp. 112-122, 2008.

[11] C. F. Macrae, I. J. Bruno, J. A. Chisholm et al., "Mercury CSD 2.0- new features for the visualization and investigation of crystal structures," Journal of Applied Crystallography, vol. 41, no. 2, pp. 466-470, 2008.

[12] The PyMOL Molecular Graphics System, Version 1.3, Schrödinger, LLC, 2010. 

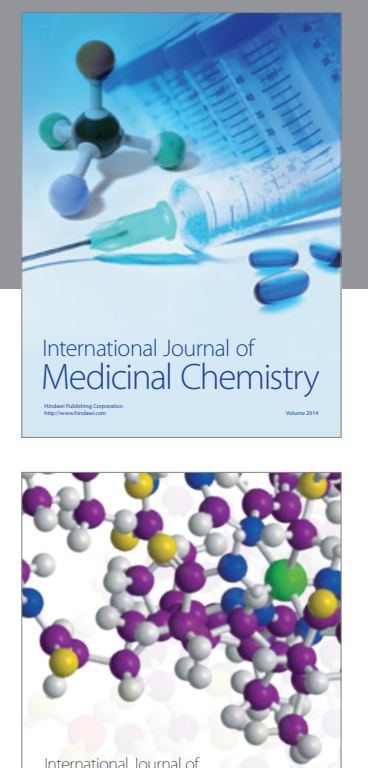

\section{Carbohydrate} Chemistry

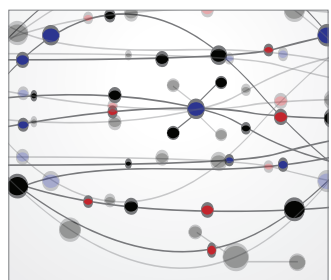

The Scientific World Journal
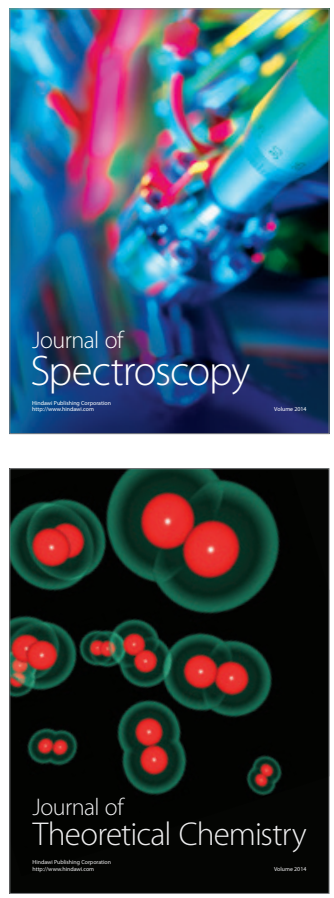
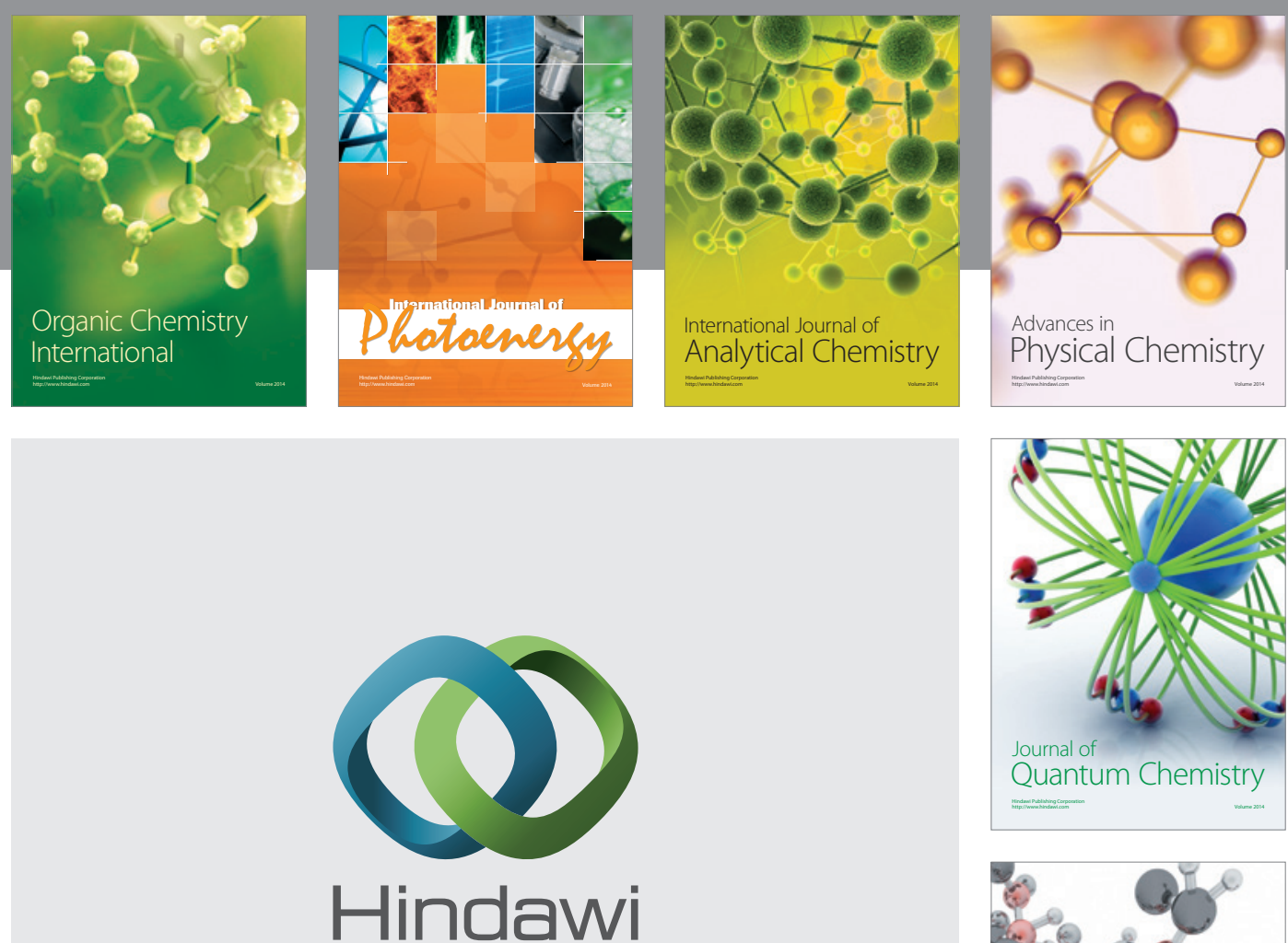

Submit your manuscripts at

http://www.hindawi.com

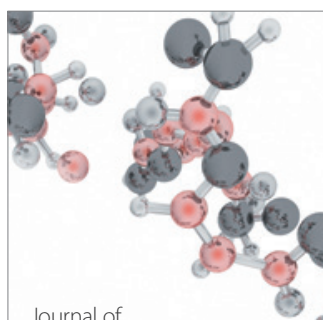

Analytical Methods

in Chemistry

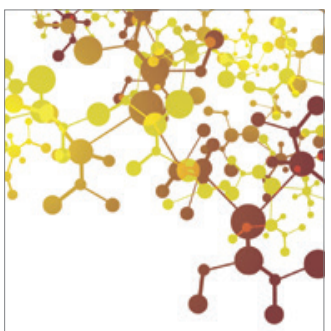

Journal of

Applied Chemistry

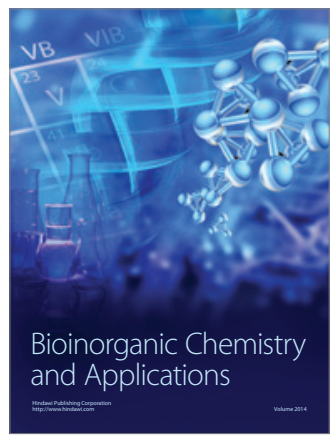

Inorganic Chemistry
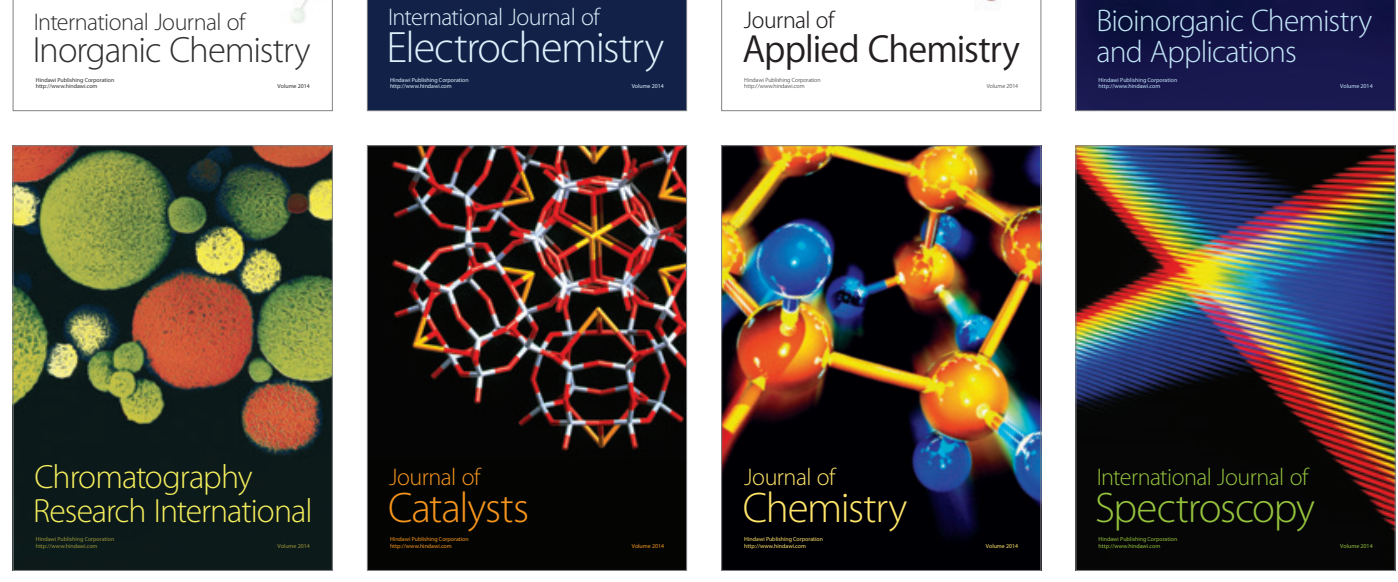